\title{
Industrial Application of Magnetoelastic Force and Torque Sensors
}

\author{
A. Bieńkowski, R. SzewczyK* And J. SAlach \\ Institute of Metrology and Biomedical Engineering, Warsaw University of Technology \\ św. A. Boboli 8, 02-525 Warszawa, Poland
}

\begin{abstract}
Due to their sensitivity, robustness and the flat shape, the magnetoelastic sensors create new possibilities of industrial applications. This paper presents the results of the field tests of using the magnetoelastic sensors with amorphous alloy ring-shaped cores for ignition detection in locomotive's diesel engines as well as measurements of the torque during the operation of ball valves. Presented results confirm usability of amorphous alloy based, magnetoelastic sensors for specific industrial applications.
\end{abstract}

PACS numbers: 75.80. $+\mathrm{q}, 07.10 . \mathrm{Pz}$

\section{Introduction}

Magnetoelastic properties of newly developed soft amorphous alloys have been widely investigated from both theoretical $[1,2]$ and sensor development [3, 4] point of view. Moreover, sensors presented in literature enable to measure compressive stresses [5], tensile stresses [6] and torque [7]. On the other hand, possibility of application of such sensors in industrial environment seems to be still not sufficiently verified. For this reason we verified possibility of application of amorphous alloys-based magnetoelastic sensors in specific applications, where possibility of strain-gauge sensors application is highly limited.

One of such application is ignition detection in locomotive's diesel engine. Such detection is very important for monitoring of proper operation of engine. The lack of ignition in one of cylinders may lead to decrease of the efficiency of operation as well as to the serious malfunction of the engine. As a result lack of ignition should be detected as soon as possible. The most suitable way of ignition detection is measurement of pulse of compressive force under the binding screw of the head in a diesel engine. Strain-gauge sensors are not suitable for such application due to the fact that sensor has to be flat as well as it has to operate in very difficult environmental conditions.

Measurement of torque during the opening and closing of the ball valve gives information about the ball malfunction or wearing. On the other hand, in industrial applications such sensor has to rotate together with rotation of the ball valve shift. For this reason possibility of application of typical strain-gauge sensors is very limited, which justifies application of magnetoelastic sensors.

\section{Results of the field tests}

For ignition detection in diesel engines of locomotives SM-42, specialized magnetoelastic sensor for compressive

\footnotetext{
* corresponding author; e-mail: szewczyk@mchtr.pw.edu.pl
}

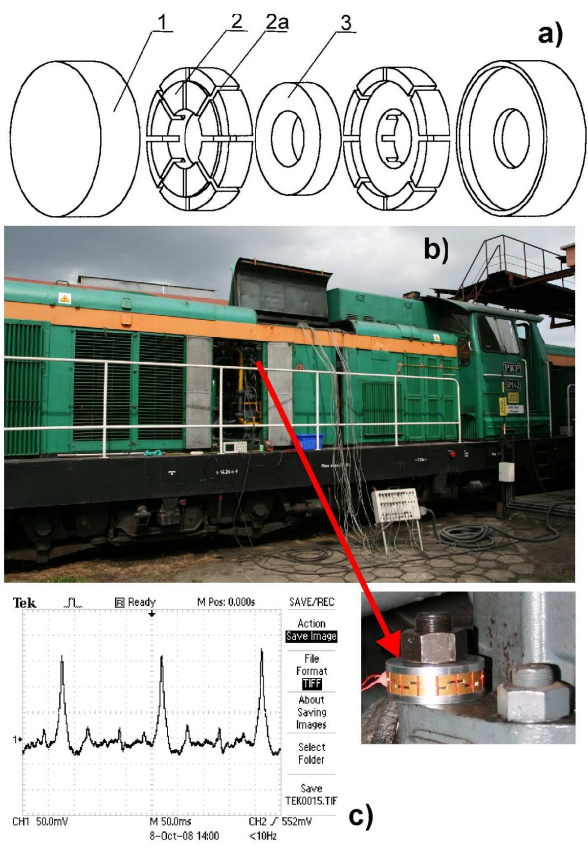

Fig. 1. Magnetoelastic compressive stress sensors: (a) schematic diagram of the sensor: 1 - magnetoelastic sensing core, 2 - nonmagnetic backings with grooves 2 a for winding, 3 - base backings, (b) magnetoelastic sensor under the binding screw of the head in a diesel engine of SM-42 locomotive, (c) plot of output signal from the magnetoelastic sensor (peaks connected with ignition in diesel engine's cylinders are clearly visible).

stress measurements has been developed. In such sensor uniform compressive stresses are applied perpendicularly to the direction of the magnetizing field, utilizing device [8] presented in Fig. 1a. Magnetoelastic, ring-shaped sensing core was made of $\mathrm{Fe}_{40} \mathrm{Ni}_{38} \mathrm{Mo}_{4} \mathrm{~B}_{18}$ amorphous alloy in as-quenched state. This core was placed between two nonmagnetic backings, which enables core to be winded. This method of application of uniform compressive stresses to the ring-shaped core may be also 

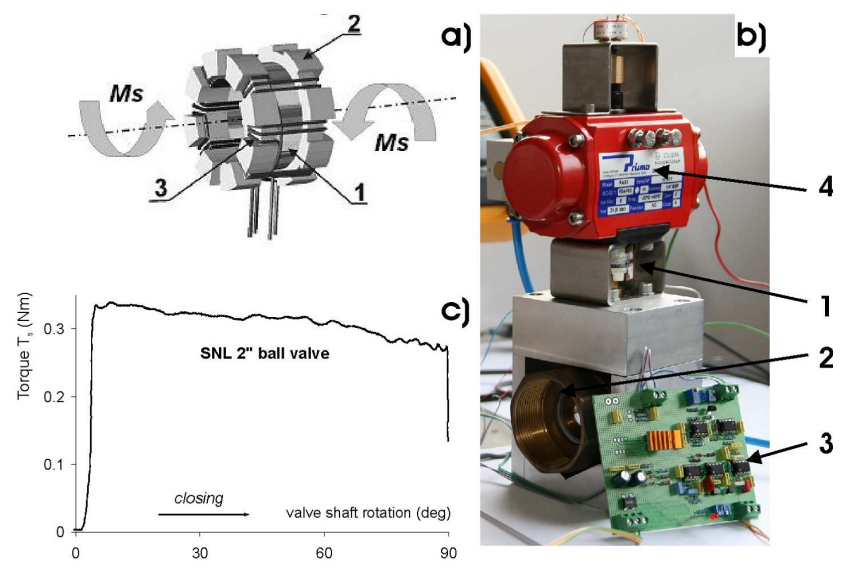

Fig. 2. Magnetoelastic torque sensors: (a) schematic diagram of the torque sensor: 1 - magnetoelastic sensing core, 2 - nonmagnetic backings fixed to the core, 3 - winding, (b) specialized setup for testing of ball valves: 1 - magnetoelastic torque sensor, 2 - ball valve SNL $2^{\prime \prime}, 3$ - electronic circuit of magnetoelastic transducer, 4 - pneumatic actuator for valve control, (c) torque $T_{\mathrm{s}}$ versus angle dependence during the closing of ball valve.

used for fundamental research in the area of magnetoelastic properties of newly developed magnetic materials [9]. Figure 1b presents location of magnetoelastic sensor under the binding screw of the head in a diesel engine of SM-42 locomotive, whereas Fig. 1c presents the plot of output signal from the magnetoelastic sensor. It should be indicated that in Fig. 1c peaks connected with ignition in diesel engine's cylinders are clearly visible.

Tests of possibility of application of magnetoelastic sensors for torque monitoring during the closing of a valve was made on SNL $2^{\prime \prime}$ ball valve for industrial applications. Principles of operation of magnetoelastic torque sensors [7] are presented in Fig. 2a. Magnetoelastic core (1) made of $\mathrm{Fe}_{70} \mathrm{Ni}_{8} \mathrm{Si}_{10} \mathrm{~B}_{12}$ alloy in as-quenched state is fixed to special backings (2), which enable core to be winded by windings (3), whereas torque is applied by special shafts. Figure $2 \mathrm{~b}$ presents specialized setup for testing of ball valves. Results of these tests are presented in Fig. 2c. It should be indicated that nearly flat plot of torque was observed during the closing of the ball valve.

\section{Conclusion}

The presented results confirm that magnetoelastic sensors may be successfully implemented for industrial applications. Moreover, for both presented applications, the magnetoelastic sensors are better than commercially available strain-gauge sensors. Applied magnetoelastic sensors are robust, reliable and resistant for environmental conditions. For this reason developed magnetoelastic sensors should be considered as important alternative for industrial applications.

\section{Acknowledgments}

This work was supported by Polish Ministry of Science and Higher Education within research grant N N505 465338 .

This work has been supported by the European Union in the framework of European Social Fund through the Warsaw University of Technology Development Programme.

\section{References}

[1] D.C. Jiles, Introduction to Magnetism and Magnetic Materials, Chapman\&Hall, London 1998.

[2] M.J. Sablik, H. Kwun, G.L. Burkhardt, D.C. Jiles, J. Appl. Phys. 61, 3799 (1987).

[3] J.M. Barandiaran, J. Gutierrez, Sensors Actuators A 59, 38 (1997).

[4] H. Chiriac, M. Pletea, E. Hristoforou, Sensors Actuators $A$ 81, 166 (2000).

[5] A. Bieńkowski, R. Szewczyk, Sensors Actuators A 113, 270 (2004).

[6] J. Salach, R. Szewczyk, A. Bieńkowski, A. Kolano-Burian, M. Falkowski, Acta Phys. Pol. A 118, 775 (2010).

[7] J. Salach, A. Bieńkowski, R. Szewczyk, J. Magn. Magn. Mater. 316, e607 (2007).

[8] A. Bieńkowski, R. Szewczyk, Polish Patent P-345758, 2001.

[9] R. Szewczyk, J. Phys. D, Appl. Phys. 40, 4109 (2007). 